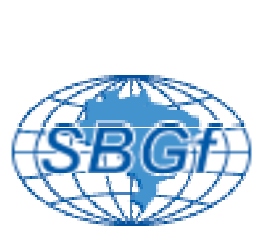

\title{
Resenha dos levantamentos da estrutura crustal no Brasil utilizando o método de refração sísmica profunda.
}

\author{
Jesus Berrocal, Fábio André Perosi \& Célia Fernandes \\ Instituto de Astronomia, Geofísica e Ciências Atmosféricas, Universidade de São Paulo, São Paulo, Brasil
}

Copyright 2004, SBGf - Sociedade Brasileira de Geofísica

Este texto foi preparado para a apresentação no I Simpósio de Geofísica da Sociedade Brasileira de Geofísica, São Paulo, 26-28 de setembro de 2004. Seu conteúdo foi revisado pela Comissão Tecno-científica do I SR-SBGf mas não necessariamente representa a opinião da SBGf ou de seus associados. E proibida a reprodução total ou parcial deste material para propósitos comerciais sem prévia autorização da SBGf

\section{Resumo (Arial Bold, 9)}

Neste trabalho efetua-se uma descrição dos principais levantamentos de refração sísmica profunda realizados no território brasileiro, desde 1970 até o presente. São apresentados os respectivos modelos da crosta e a localização desses levantamentos.

\section{Introdução}

A Sismologia, assim como a própria Geofísica, são ciências implantadas no Brasil em épocas relativamente recentes. Antes da década de 1970 não existia nenhum grupo de pesquisa no Brasil dedicado a pesquisas e levantamentos geofísicos, e menos ainda sismológicos, devido à falta de tradição neste campo pelo nível muito baixo de atividade sísmica neste país. Os levantamentos geofísicos para prospecção e exploração de petróleo e de grandes jazidas minerais no Brasil, quase na sua totalidade eram executados por empresas geofísicas internacionais.

A partir da década de 1970 vários grupos de pesquisa em geofísica começaram a ser implantados no Brasil, interessados tanto nos aspectos aplicados com fins econômicos quanto para estudos do interior e da dinâmica de nosso planeta. Nessa época também começou o interesse pelos estudos sismológicos que incitaram os estudos sobre estrutura da crosta e da litosfera no Brasil.

No presente trabalho é apresentada uma descrição dos principais levantamentos da estrutura crustal no Brasil utilizando o método de refração sísmica profunda (RSP), executados desde a década de 1970 até o presente (ver Fig. 1). Outros trabalhos com dados sismológicos para estudos da estrutura crustal estão indicados também nessa figura

\section{Evolução dos Levantamentos de RSP no Brasil}

Os levantamentos de RSP com fontes controladas para estudos da estrutura crustal no Brasil, podem ser divididos em dois estágios.

Estágio 1 (1973-1990): Levantamentos com registro em formato analógico, normalmente em papel ou em fita magnética, e ocupação da linha sísmica de uma só vez com espaçamento grandes ou por etapas, neste caso utilizando fontes sísmicas diferentes em aproximadamente o mesmo local. Neste estágio foram efetuados levantamentos usando explosões registradas numa rede local de sismógrafos. Hora de origem controlada pela velocidade do som ou com sensor próximo da fonte de energia.

Estágio 2 (Depois de 1990): Levantamentos com registro em formato digital utilizando disco rígido e hora de origem controlada eletronicamente. Coordenadas dos pontos de registro e da fonte e o tempo dos registradores e dos dispositivos de disparo, controlados por GPS. Os levantamentos mais recentes foram executados em linhas de $300 \mathrm{~km}$ de comprimento com explosões próprias (disparadas sem retardos e explosivos depositados em furos apropriados) a cada $50 \mathrm{~km}$, registradas em 120 pontos.

\section{Descrição dos Principais Levantamentos \\ Levantamentos do Estágio 1:}

O levantamento de refração sísmica profunda, pioneiro no Brasil, foi efetuado por Giese \& Schute (1980), numa linha de $180 \mathrm{~km}$ de extensão orientada na direção NS, composta por 34 pontos de registro em papel, ocupados em etapas diferentes. A fonte de energia foram as explosões da mina de Itabira, MG, localizada na região sudeste do Craton São Francisco. O modelo crustal determinado neste levantamento, só numa direção, foi uma crosta composta por três camadas: de 10, 28 e 40 $\mathrm{km}$ de profundidade, com $\mathrm{Vp} 6,0,6,2$ e $6,8 \mathrm{~km} / \mathrm{s}$ respectivamente, com uma zona de transição de $8,0 \mathrm{~km} / \mathrm{s}$ seguida pelo manto com 8,2 km/s. (ver Fig 2a).

O levantamento de RSP efetuado por Bassini (1986) foi numa linha entre Sorocaba, SP e Itatiaia, RJ, com uma extensão máxima de $260 \mathrm{~km}$, utilizando fogos de várias pedreiras localizadas na porção sudoeste da linha, registradas em até 15 pontos de registro, alguns deles em estações sismográficas fixas da RESUSP e outros pontos portáteis instalados em etapas diferentes, com registro em fita magnética. $O$ modelo determinado para a crosta foi de duas camadas com profundidades de 7,6 e $36 \mathrm{~km}$ e $\mathrm{Vp} \mathrm{5,7} \mathrm{e} \mathrm{6,3} \mathrm{km/s} \mathrm{respectivamente.} \mathrm{Debaixo} \mathrm{da}$ Moho obteve uma Vp de $8,1 \mathrm{~km} / \mathrm{s}$.

Alarcon (1989) e Pedreschi (1989) trabalharam com dados de três linhas de RSP, duas de $240 \mathrm{~km}$ e outra de 100 km de extensão, orientadas nas direções N, NW-W e SW a partir da mina Caraíba Metais, respectivamente. 


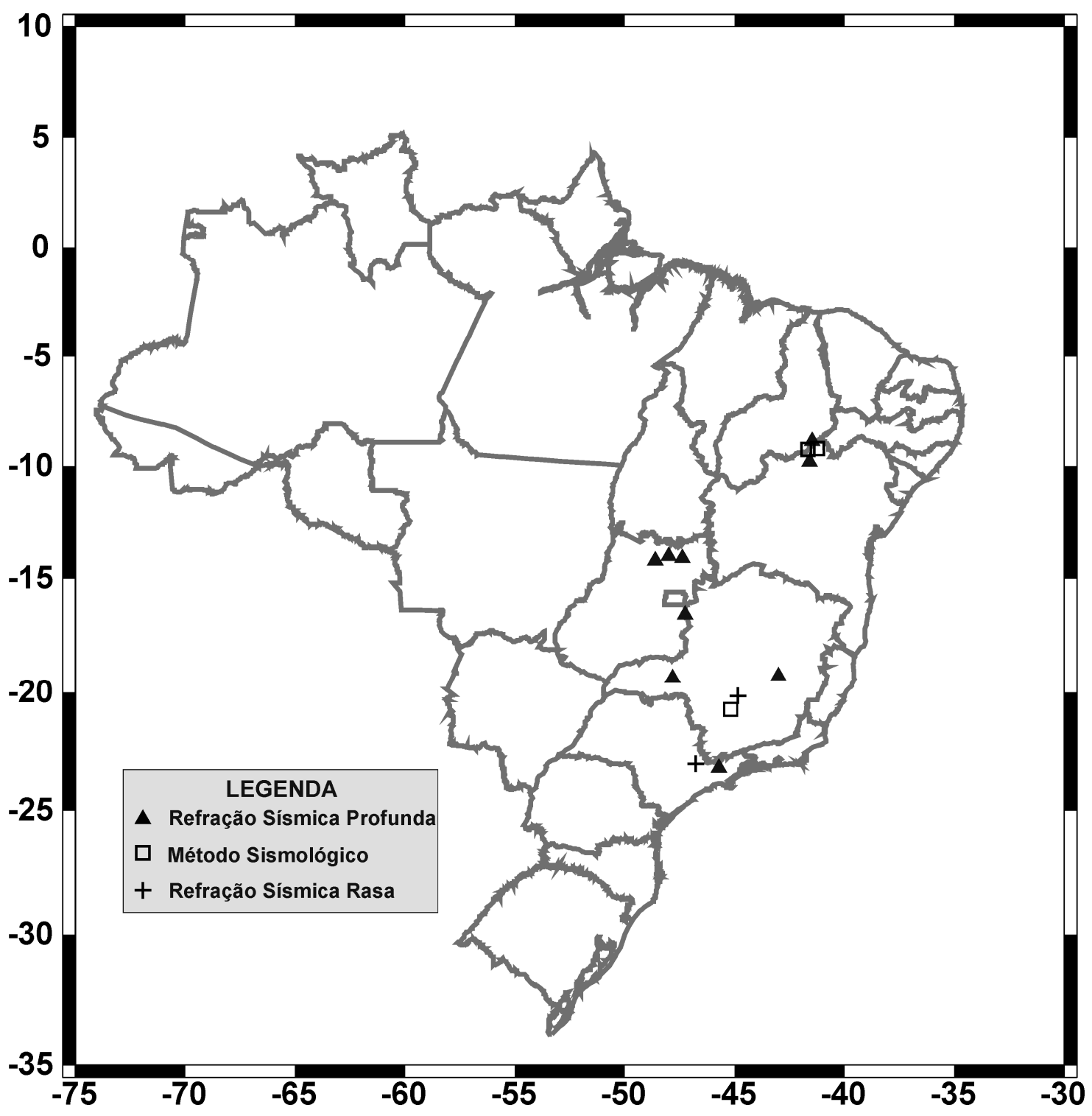

Figura 1 -Mapa mostrando a localização dos levantamentos de refração sísmica profunda efetuada no Brasil, assim como outros levantamentos para estudos da estrutura crustal. 
Foram utilizados até 17 pontos com registro simultâneo para cada explosão, em cada linha. O modelo obtido por esses autores consta de um crosta de duas camadas com 27 e $44 \mathrm{~km}$ de profundidade com Vp 6,2 e 7,2 km/s respectivamente. A Vp debaixo de Moho é de $8.1 \mathrm{~km} / \mathrm{s}$ (ver Fig. 2b).

\section{Levantamentos do Estágio 2:}

Uma linha inconclusa de RSP foi executada na porção sul do Craton de São Francisco por Pereira (1995), entre as cidades de Formiga e Divinópolis em MG. A porção da linha executada permitiu atingir somente a crosta superior composta por uma camada de $4 \mathrm{~km}$ de espessura e Vp de $5,8 \mathrm{~km} / \mathrm{s}$ sobreposta a outra camada com $\mathrm{Vp} 6,5 \mathrm{~km} / \mathrm{s}$. Neste experimento foram utilizados sismógrafos multicanais com registro no formato digital.

Um trabalho realizado por Assumpção (2004) apresenta um modelo crustal na região sul do Craton de São Francisco, utilizando registros de microtremores e de explosões efetuadas nessa região. O modelo proposto está composto por uma crosta de duas camadas com profundidades de 22 e $43 \mathrm{~km}$ e $V p$ de 6,2 e $6,7-7,0 \mathrm{~km} / \mathrm{s}$, respectivamente e um manto com Vp $8,3 \mathrm{~km} / \mathrm{s}$ (ver Fig. 2c).

Em 1997 foi realizada uma linha experimental, com direção N-S, entre Minaçu, GO, e Brasília, DF, utilizando 20 estações com registro digital com explosões nos extremos, espalhadas nos $260 \mathrm{~km}$ dessa linha. O modelo obtido por Soares et al., (2001) é apresentado na Fig. 2d, com um modelo composto por três camada de 5, 30 e 42 $\mathrm{km}$ de profundidade e $\mathrm{Vp} \mathrm{5,3,6,2} \mathrm{e} \mathrm{7,0,} \mathrm{km/s}$ respectivamente. O manto com $\mathrm{Vp} 8,2 \mathrm{~km} / \mathrm{s}$.

Em 1998 foram efetuadas três linhas de RSP como parte do projeto temático para estudar a Província Tocantins. nas regiões de Porangatu e Cavalcante, GO e uma terceira em Minas Gerais. Foram as primeiras linhas de refração sísmica profunda efetuadas no Brasil, com explosões próprias e com tempo de início controlado, utilizando 120 pontos de registro, em formato digital. Os modelos mostram uma crosta de três camadas. Os resultados destes trabalhos serão apresentados e discutidos por outros autores no presente simpósio. $\mathrm{Na}$ Fig. 2e são apresentados os modelos preliminares obtidos por Soares et al. (2001) para os tiros em Goiás.

\section{Conclusões}

Os levantamentos de RSP no Brasil têm evoluído desde a década de 1970 até fins da década de 1990, até atingir uma qualidade comparável com trabalhos efetuados em outros países. Atualmente é possível contar no Brasil com os meios tecnológicos e o pessoal capacitado necessários para efetuar esse tipo de experimento.

Os modelos apresentados têm características semelhantes e estão de acordo com modelo crustais em regiões de escudo continental.

\section{Referências}

Alarcon, S., 1989. Modelo preliminar da estrutura crustal com dados da linha de refração sísmica Caraíba (BA) Trindade (PE). Trabalho de Graduação-IAG/USP

Assumpção, M., 1994. Preliminary crustal model for SE Brazilian shield based on local earthquakes in southern Minas Gerais. In: Regional Assembly in South America.

Bassini, A. M., 1986. Levantamento sismográfico na região Sudeste do Brasil. Dissertação de mestrado IAG/USP.

Giese, P. \& Schute, J., 1980. Resultados das medidas de sísmica de refração a Leste da Serra do Espinhaço, MG, Brasil. In: Nuevos Resultados de la Investigación Geocientífica Alemana en Latino América, Deitado por W. Zeil. Printed by Georg Houser pp 44-50.

Predreschi, E. S., 1989. Modelo regional preliminary da estrutural crustal na região do Reservatório de Sobradinho com dados de refração sísmica profunda. Tabalho de Graduação IAG/USP.

Pereira, M. R. S., 1995. Perfil sísmico na região de Formiga-MG utilizando o método fr refração sísmica profunda. Trabalho de Graduação IAG/USP.

Soares, J. E. P., Berrocal, J. \& Antubes, J. A., 2001. The Cavalcante and Minaçu-Brasilia deep seismic refraction lines: a travel time interpretation of crustal structure in Central Brazil. 7o. Congresso Internacional da SBGf Resumos expandidos, Salvador, BA. Vol II, p. 1308-1311 


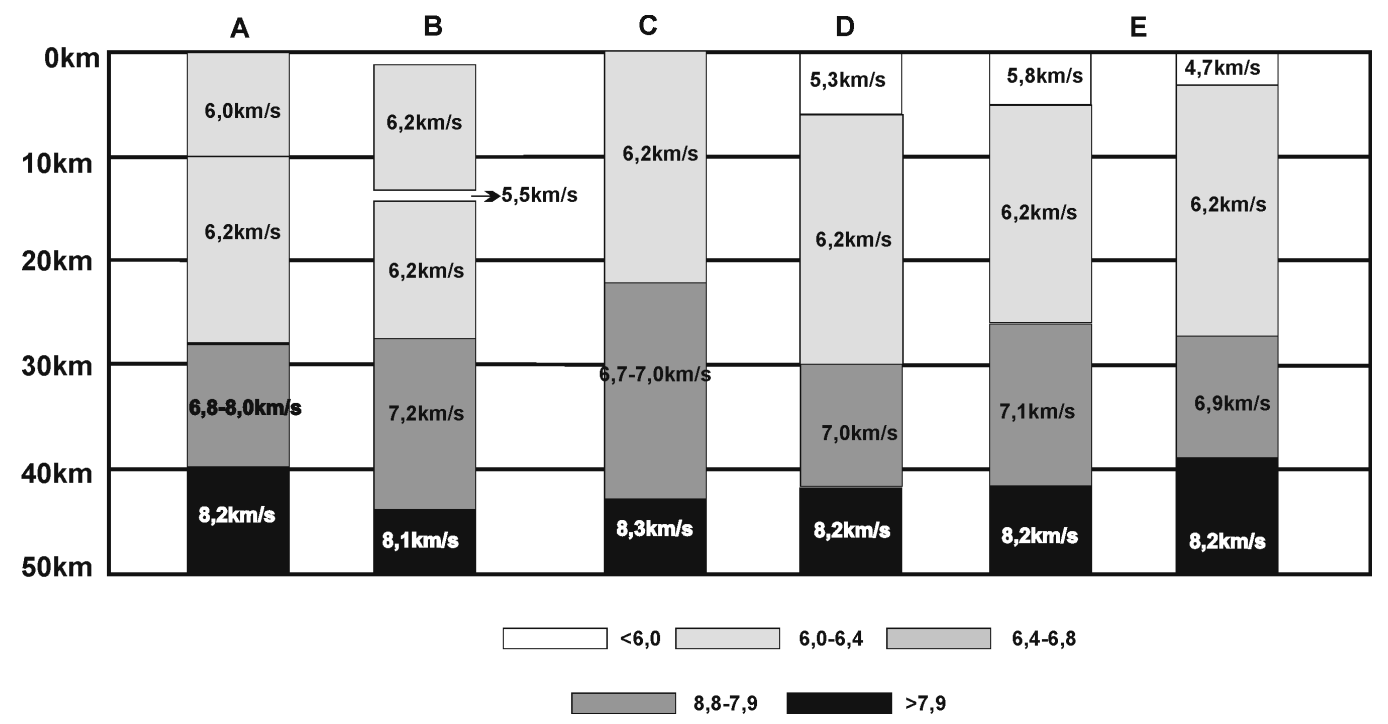

Figura 2 - Modelos da estrutura crustal de acordo com os autores mencionados no texto (Ref. Perosi, 2002) 